\title{
Nondestructive, Microwave Testing of Compression Strength and Moisture Content of Green Molding Sands
}

\author{
Beata Gal ${ }^{1}$ (D) $\cdot$ Daniel Nowak ${ }^{1}$
}

Received: 25 March 2021 / Accepted: 4 September 2021 / Published online: 24 September 2021

(c) The Author(s) 2021

\begin{abstract}
A nondestructive microwave testing method to control the green compression strength and moisture content was proposed and demonstrated. There are various green moulding sands, both qualitative (bentonite type) and quantitative (bentonite and water content), prepared. The permittivity measurements were performed by cavity perturbation technique (CPT) at $2.45 \mathrm{GHz}$. Relative complex permittivity of the bentonite bonded moulding sands is proportional to the bentonite and moisture content and is inversely proportional to green compressive strength. It was shown that the obtained permittivity value of the molding sands be used to investigate the green compression strength and moisture content.
\end{abstract}

Keywords Green moulding sands $\cdot$ Bentonite $\cdot$ Moisture content $\cdot$ Green compression strength $\cdot$ Microwave $\cdot$ Complex relative permittivity

\section{Introduction}

Green moulding sands, consisting of $2-5 \%$ water $\left(\mathrm{H}_{2} \mathrm{O}\right)$ and ceramic materials such as $85-95 \%$ highsilica sand $\left(\mathrm{SiO}_{2}, \quad \mathrm{Fe}_{2} \mathrm{O}_{3}\right), \quad 5-10 \%$ bentonite clay $\left(\left(\mathrm{Al}_{1,67} \mathrm{Mg}_{0,33}\right)\left[\left(\mathrm{OH}_{2}\right) \mid \mathrm{Si}_{4} \mathrm{O}_{10}\right] \mathrm{Na}_{0,33}\left(\mathrm{H}_{2} \mathrm{O}\right)_{4}\right)$ and $0.5-2 \%$ additives such as carbon-base materials or dextrin, are the oldest compositions used for molds and cores in casting of ferrous metals [1-4].

Bentonites and bentonite clays are aluminosilicates with montmorillonite group minerals as the major component. Structurally, they are composed of three-layer packets: an aluminosilicate layer enclosed between two silicotene layers. The distances between the packets depend on the exchangeable cation and change under the influence of water; when water saturation increases, the distances increase. The effect of changing distances is the swelling of montmorillonites and the occurrence of inter-packet water with a rigid network. The process of saturation and elimination of inter-packet

Beata Gal

beata.gal@pwr.edu.pl

Daniel Nowak

daniel.nowak@pwr.edu.pl

1 Department of Lightweight Elements Engineering, Foundry and Automation, Wrocław University of Science and Technology, 27 Wybrzeże Wyspiańskiego St, 50-270 Wrocław, Poland water occurs easily because montmorillonite absorbs and gives up water when in contact with its surroundings. From the technological point of view, dry components of classical molding sand: matrix and binder do not have any cohesion and functional properties, either loosely mixed or mechanically compacted. The addition of water only guaranteed these properties. Water plays a significant role in physics of the mixture of materials such as moulding sand and its content determines their physicochemical state and properties. Water in sand and clay mixture causes formation of rigid, ordered systems (Fig. 1) consisting of layers of water molecules on the sand and clay surface. These cause adhesion of the adjacent outer surfaces and bonding of the sand grains $[5,6]$.

In a study of kaolinite clays, it was found that dielectric losses and the frequencies at which they occur depend on the types and strength of the intermolecular bonds, and this provides a potential way to evaluate the strength properties of subgrade soils and road aggregates by measuring their dielectric properties [7].

The requirements for the properties of moulding sands are based on the size, shape and design of the casting and the planned moulding process (for instance: hand ramming, automated moulding) [3, 4]. The most important properties of the green moulding sands include: compactibility, moisture content, specimen weight, permittivity, green compression strength $[3,8]$. Green compression strength is a crucial property of the moulding sand, which represents 


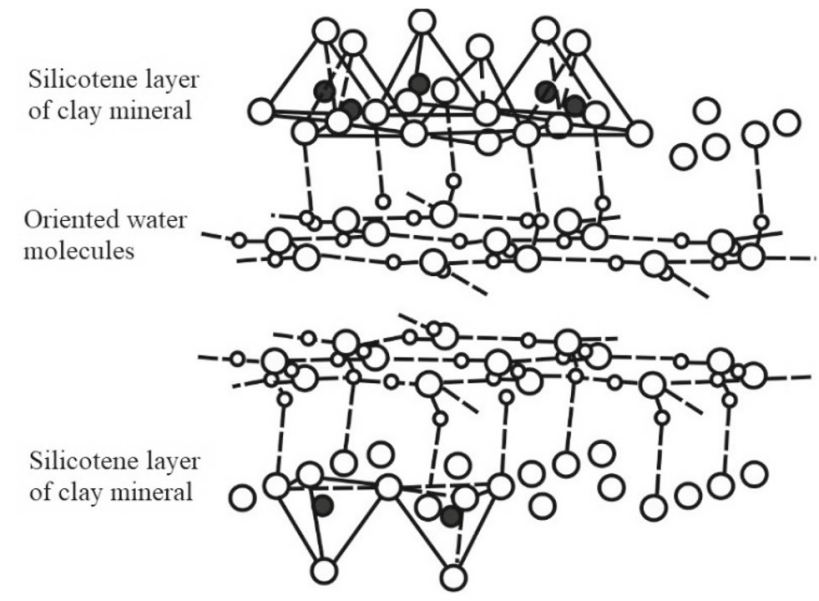

Fig. 1 Water network between clay mineral packets by Hendricks and Jefferson [6]

its ability to maintain the shape of the mold during both molding, transport and casting process [9]. It depends on moisture, bentonite content, compaction degree. Typically, the values of these properties are determined by separate experimental studies such as: testing the methylene blue, the $\mathrm{Cu}(\mathrm{II})$-triethylenetetramine complex adsorption method (Cu(II)-TET method) or the infrared spectroscopy (FTIR) method for determination of the bentonite content or methods that use image recognition, gravimetric method for moisture content and compression strength test [4, 10-14]. The image recognition method is based on decomposing color images into three-channel images and then performing gray subtraction calculation and gray level transformation of gray images. In the last step, the outer circle of light blue halo and inner circle of blue patch are extracted and their area ratio is calculated [12].

The development of the testing area of the properties of moulding sands is now determined by the requirements of Industry $4.0[15,16]$. The response to the ever-increasing demands is to develop a process for testing the properties of the moulding sands in a simultaneous, quick and nondestructive method.

Microwave testing of nonconducting materials such as lossless dielectrics and low lossy dielectrics is used to determine the properties such as porosity, material composition, delamination of layers, moisture, and contamination content [17]. Microwave testing of materials involves determining the relationship between electrical (complex relative permittivity) and mechanical (strength), thermal, physical properties thus become a competitive method for known measurement techniques. This paper presents a range of non-destructive testing applications using microwave energy and the advantages of using such testing [18]. A review and possibilities of application of various microwave testing techniques on the example of glass fiber reinforced polymer composites is presented in the article [19].

Formula (1) describes complex relative permittivity, one of the dielectric properties [20]:

$\varepsilon_{r}=\varepsilon_{r}^{\prime}-i \varepsilon_{r}^{\prime \prime}$

where $\varepsilon_{r}^{\prime}$ is the real part of the relative complex permittivity, $i$ is an imaginary unit, $\varepsilon_{r}^{\prime \prime}$ is the imaginary part of the relative complex permittivity. The $\varepsilon_{r}^{\prime}$ characterises the ability of the material to store microwave energy, and the $\varepsilon_{r}^{\prime \prime}$ imaginary part describes the thermal conversion. The key features of the permittivity variability are: temperature, frequency, moisture content, and qualitative composition. The authors of the study [21] have showed that the dielectric properties of quartz sand depend linearly on temperature and moisture content. In article [22], the influence of the microwave frequency in the range 0.1 to $10 \mathrm{GHz}$ has been proven in real and imaginary part of the permittivity of dry silica sand. Many research has shown that knowledge of complex relative permittivity, depending on the physical, chemical or technological factors chosen, allows for rapid and non-destructive determination of the moisture content of the materials containing sand [23-25]. Concrete examining have shown that the increase in permittivity has resulted in a decrease in compression strength [26].

Table 1 shows selected relationships for determining the electrical permittivity of mixtures. Using selected, described mathematical models gives satisfactory results when the differences in the permeability values of individual phases are small. When they are large, the application of the above mathematical models to determine the permeability values is subject to large errors [23]. The only solution, when determining the dielectric properties of mixtures with such different dielectric parameters of individual phases, is to determine semi-empirical or empirical mathematical models based on laboratory tests. The literature analysis has shown that the empirical model gives a better description of the dielectric behavior of different soil-water mixtures than the existing relationships given in Table $1[23,27]$.

Determination of mathematical models on the basis of experimental data, not considering the modeled phenomena, is classified as soft mathematical modeling. This modeling brings significant benefits: it reduces the time and cost of introducing new products into production, as it allows to avoid costly workshop tests and additionally facilitates the forecasting of technological process parameters [29].

The aim of this work is to develop a nondestructive, microwave testing method at $2.45 \mathrm{GHz}$ for the simultaneous determination of the moisture content and green compression strength of the moulding sands bonded with bentonite. 
Table 1 Formulas for determining the electrical permittivity of mixtures [28]

\begin{tabular}{ll}
\hline Author & Formula \\
\hline Rayleigh & $\frac{\varepsilon_{\text {eff }}-\varepsilon_{e}}{\varepsilon_{\text {eff }}+\varepsilon_{e}}=V_{i}\left(\frac{\varepsilon_{n}-\varepsilon_{e}}{\varepsilon_{n}+2 \varepsilon_{e}}\right)$ \\
Wiener & $\frac{\varepsilon_{\text {eff }}-\varepsilon_{e}}{\varepsilon_{\text {eff }}+u}=V_{i}\left(\frac{\varepsilon_{n}-\varepsilon_{e}}{\varepsilon_{n}+u}\right)$ \\
Böttcher & $\frac{\varepsilon_{\text {eff }}-\varepsilon_{e}}{3 \varepsilon_{\text {eff }}}=V_{i}\left(\frac{\varepsilon_{n}-\varepsilon_{h}}{\varepsilon_{n}+2 \varepsilon}\right)$ \\
Polder, van Santer & $\varepsilon_{\text {eff }}-\varepsilon_{e}=\sum_{i=1}^{N} V_{i}\left(\varepsilon_{n}-\varepsilon_{e}\right) \cdot \frac{1}{3} \sum_{j=1}^{3}\left[1+N_{j}\left(\frac{\varepsilon_{n}}{\varepsilon_{\text {eff }}}-1\right)\right]^{-1}$ \\
Lootenga & $\varepsilon^{\frac{1}{3}}=V_{i} \varepsilon_{n}^{\frac{1}{3}}+\left(1-V_{i}\right) \varepsilon_{e}^{\frac{1}{3}}$ \\
Sihvola, Kong & $\varepsilon_{\text {eff }}=\varepsilon_{e}+\sum_{i=1}^{3} \frac{V\left(\varepsilon_{e}-\varepsilon_{h}\right)\left[\varepsilon_{a}+N_{i}\left(\varepsilon_{e f f}-\varepsilon_{e}\right)\right]}{3\left[\varepsilon_{a}+N_{i}\left(\varepsilon_{n}-\varepsilon_{e}\right)\right]}$ where $\varepsilon_{a}=\varepsilon_{e}+a\left(\varepsilon-\varepsilon_{e}\right) 0 \leq a \leq 1$ \\
\hline
\end{tabular}

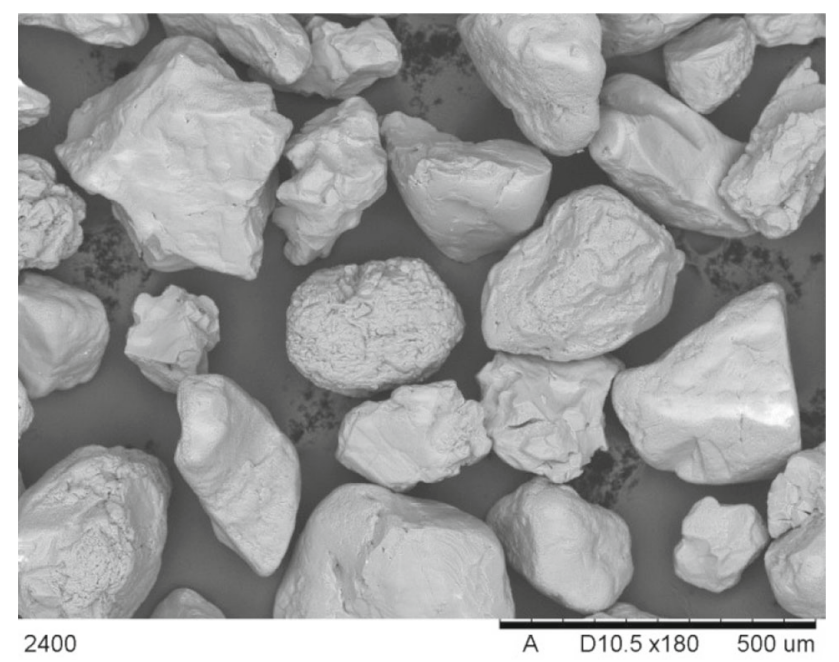

Fig. 2 Surface topography of high-silica sand grains, SEM $\times 180$

Table 2 Selected physical and chemical properties of bentonites [30, 31]

\begin{tabular}{llll}
\hline Parameter & Bentonite A & Bentonite B & Bentonite C \\
\hline $\begin{array}{l}\text { Water content max. (\%) } \\
\text { Montmorillonite content }\end{array}$ & 12 & 12 & 14 \\
$\quad$ min. (\%) & & 80 & 90 \\
$\begin{array}{l}\text { Carbonate content max. } \\
(\%)\end{array}$ & 5 & 5 & 5 \\
$\begin{array}{l}\text { Swelling index min. }\left(10^{6}\right. \\
\left.\mathrm{m}^{3} / 2 \mathrm{~kg}\right)\end{array}$ & 17 & 25 & 20 \\
\hline
\end{tabular}

\section{Materials and Methods}

For the moulding sand grain, class $1 \mathrm{~K}$ high-silica sand (Fig. 2) with a major fraction of $0.200 / 0.160 / 0.315$, meeting standard PN-85/H-11001 (mine 'Grudzeń Las' Poland) was used. This material was chosen due to the fact there is the advantageous relationship between technological properties, price and availability, and is most widely used in many foundries in the country and worldwide. The binding material was distilled water and three types of sodium bentonite that differed in montmorillonite content (Table 2).
Measurements of permittivity and moisture content were carried out for 48 moulding sands with various compositions in terms of both quality (type of bentonite A, B, C, type of sand GL, distilled water) and quantity (binding material content $5 \%, 8 \%$ and $11 \%$ and water content). The following designation (for instance GLB) was adopted, which means the moulding sand consisted of high-silica sand from the 'Grudzeń Las' mine, and Bentonite B. The moisture content of the various moulding sands ranged from 1.60 to $5.72 \%$.

The moulding sands were prepared in accordance with the literature recommendations $[4,5]$. Dry moulding sand components (silica sand and bentonite) were mixed for $120 \mathrm{~s}$ in a vertical wheel batch muller (LM-1). Then, half of the volume of water provided for the mass was introduced into the blender and mixed for another $120 \mathrm{~s}$. The rest of the water was added and mixed for $120 \mathrm{~s}$. The moulding sands were reduced by sieving through a $0.004 \mathrm{~m} \times 0.004 \mathrm{~m}$ mesh sieve. The prepared moulding sands were placed for $7200 \mathrm{~s}$ in a climatic chamber (ambient temperature $293.15 \mathrm{~K}$, humidity $60 \%$ ).

The moisture content (MC) was measured by direct gravimetric method according to the literature recommendations $[4,5]$. The density $(\rho)$ and bulk density $\left(\rho_{\mathrm{o}}\right)$ of the moulding sands were calculated as additive properties on the basis of knowledge of the weight share and density of the individual components of the moulding sands. According to the literature data [5], the bulk density, moulding sand based on quartz sand is in the range of $1400-1900 \mathrm{~kg} \mathrm{~m}^{-3}$ and the degree of compaction is $0.56-0.76$. Its value for all moulding sands adopted in the study was 0.65 .

The measurement of the real and the imaginary parts of the complex relative permittivity of moulding sands was performed by cavity perturbation technique (CPT), that allows the determination of the dielectric properties at a specific frequency $2.45 \mathrm{GHz}[17,32,33]$. A cavity resonator stand (Fig. 3a) comprises a Vector Network Analyser 8720B (Hewlett Packard, Palo Alto, California) and a rectangular resonator (standard WR340) with internal dimensions of $0.086 \mathrm{~m} \times 0.042 \mathrm{~m} \times 0.080 \mathrm{~m}$, made as a wave cavity with 
Fig. 3 View of test stand: a for resonant waveguide cavity, set up with vector circuit analyzer type HP 8720B, b universal strength testing machine $\mathrm{LRu}-2 \mathrm{e}$

Fig. 4 Procedure for determining the $\varepsilon_{r}^{\prime}$ and $\varepsilon_{r}^{\prime \prime}$ of green moulding sands
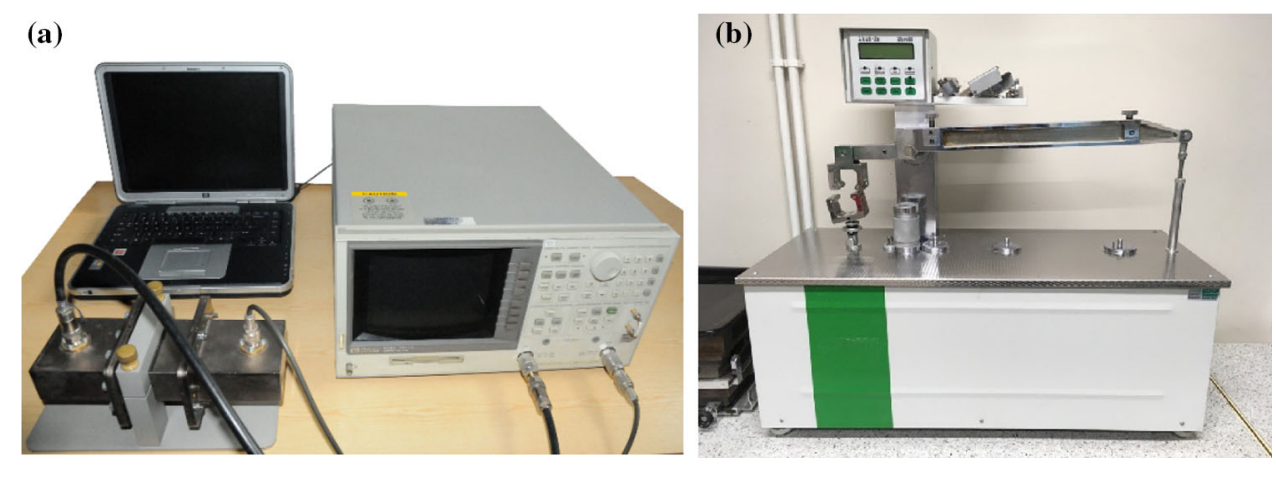

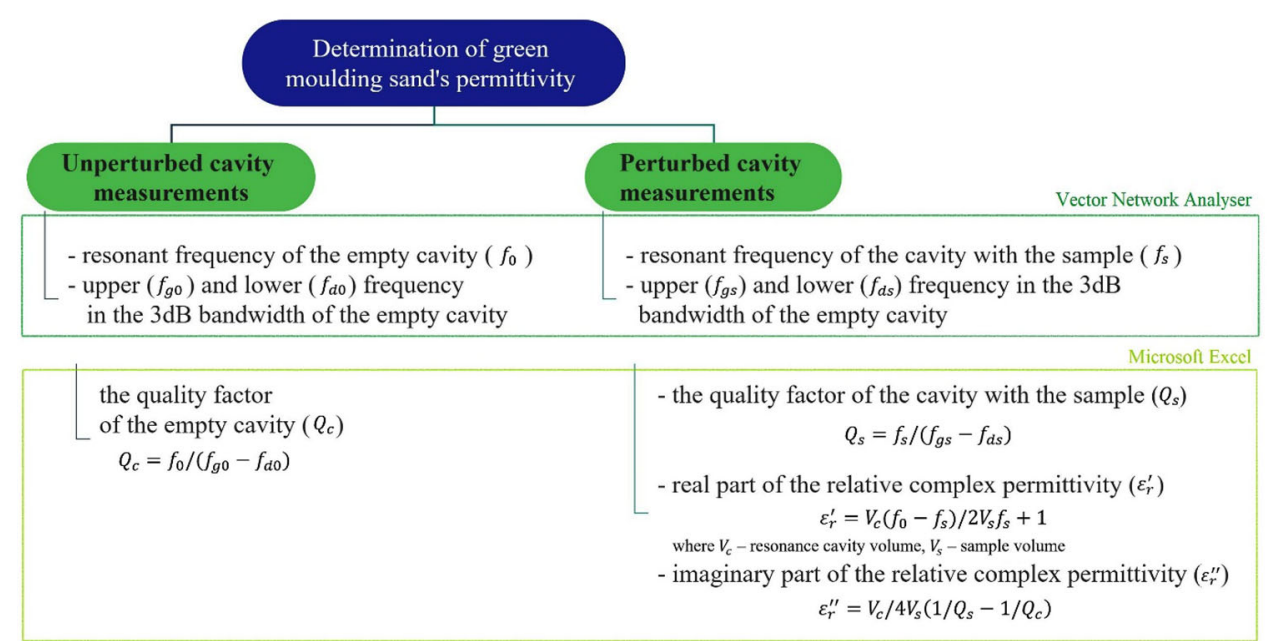

a basic type of field $\mathrm{TE}_{101}$. The measurement procedure is presented in Fig. 4.

In this prototype stand solution, the insertion of a relatively large, cylindrical, moulding sand sample into the cavity (Fig. 4) requires the waveguide set to be disconnected. This is a significant engineering change compared to similar solutions developed so far, where very small samples of the examined materials were introduced in a quartz tube or holder into the hole in the cavity wall [34-36]. Calibration measurements were carried out using polytetrafluoroethylene, which is one of the most common materials in literature with low dielectric loss. The permittivity results of the calibration samples were $\varepsilon_{r}^{\prime}=2.01$ and $\varepsilon_{r}^{\prime \prime}=0.001$, comparable to the results shown in [37-39].

Samples (Fig. 5) for permittivity tests as cylindrical laboratory shapes of $0.016 \mathrm{~m}$ diameter and $0.042 \mathrm{~m}$ height have been concentrated on laboratory tamper (LU) with a total compaction activity of approximately $1.1\left(\mathrm{~kg} \mathrm{~m}^{2} \mathrm{~s}^{-2}\right)$. The volume of the sample is less than $3 \%$ of the volume of the cavity, which ensures that the cavity perturbation is to no over $5 \%$, since the relationship to the permittivity calculation can no longer be used. The compaction degree $(\delta)$ for all test samples was 0.65 , which was calculated as the ratio of the bulk density to the density of the moulding sand.
Measurement of green compression strength (Fig. 3b) were carried out on a universal strength testing machine LRu-2e (Multiserw Morek, Brzeźnica, Poland). Standard cylindrical samples with a diameter of $0.05 \mathrm{~m}$ and a height of $0.05 \mathrm{~m}$ have been concentrated on laboratory tamper (LU). Measurement results were averaged from three trials.

The permittivity, green compression strength and moisture content measurements were conducted at an ambient temperature of $293.15 \mathrm{~K}$ and an air humidity of $50 \%$. Statistica 13.0 (Dell Software Company, Round Rock, United States of America) and Microsoft Office Excel ${ }^{\circledR} 2013$ (Microsoft ${ }^{\circledR}$, Redmond, United States of America) were used to carry out the graphical analysis and statistical calculations. A significance level of $\alpha=0.05$ was adopted [40]. Presented results are the mean value of the three measurements.

\section{Results and Discussion}

\subsection{Effect of Moisture and Bentonite Content on Permittivity}

The results of research on the influence of bentonite content (BC) and moisture content (MC) on the $\varepsilon_{r}^{\prime}$ and $\varepsilon_{r}^{\prime \prime}$ of GLA, GLB, GLC moulding sand are presented in Figs. 6, 7, 8. The 
Fig. 5 View of specimens: $\mathbf{a}$ in the waveguide measuring cavity, b on the strength testing machine
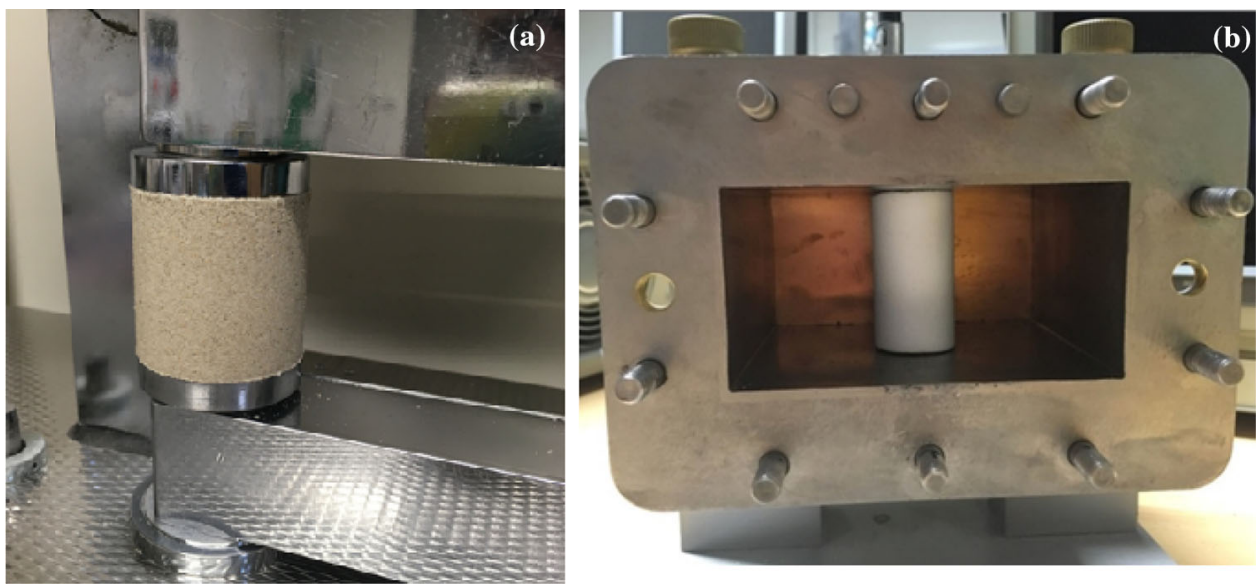

(a)

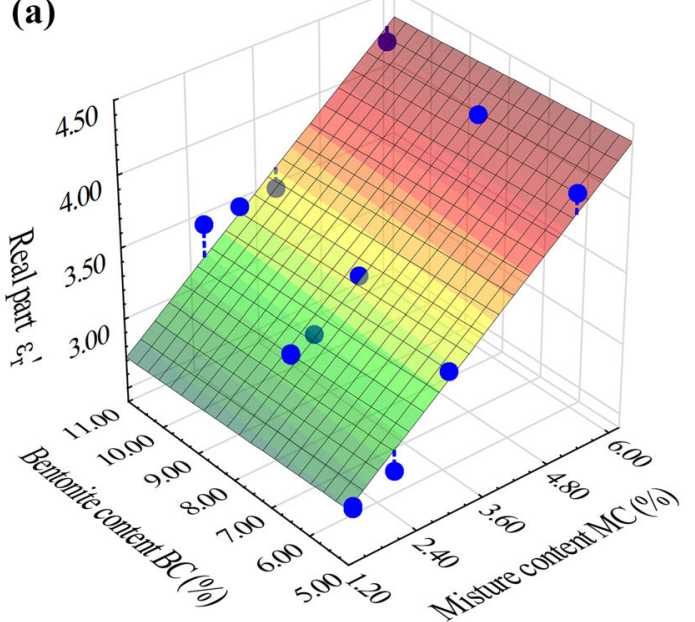

(b)

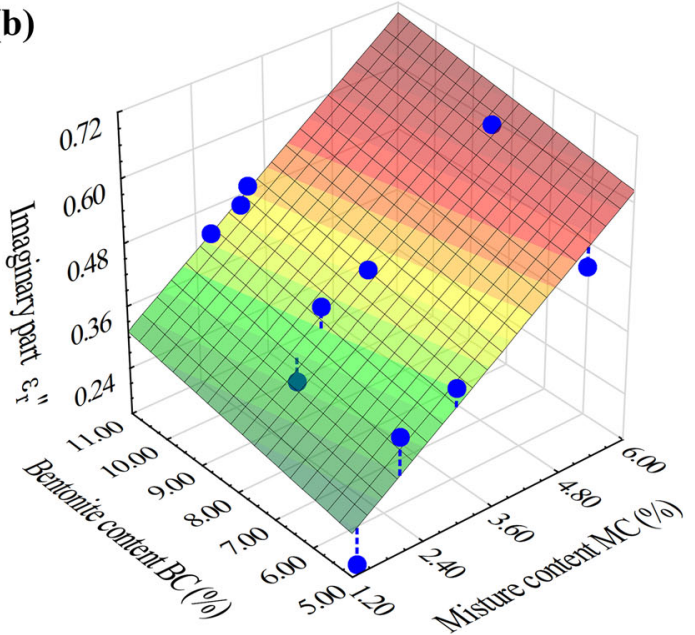

Fig. 6 The influence of moisture and bentonite content in GLA moulding sands on the $\varepsilon_{r}^{\prime}$ (a) and $\varepsilon_{r}^{\prime \prime}(\mathbf{b})$
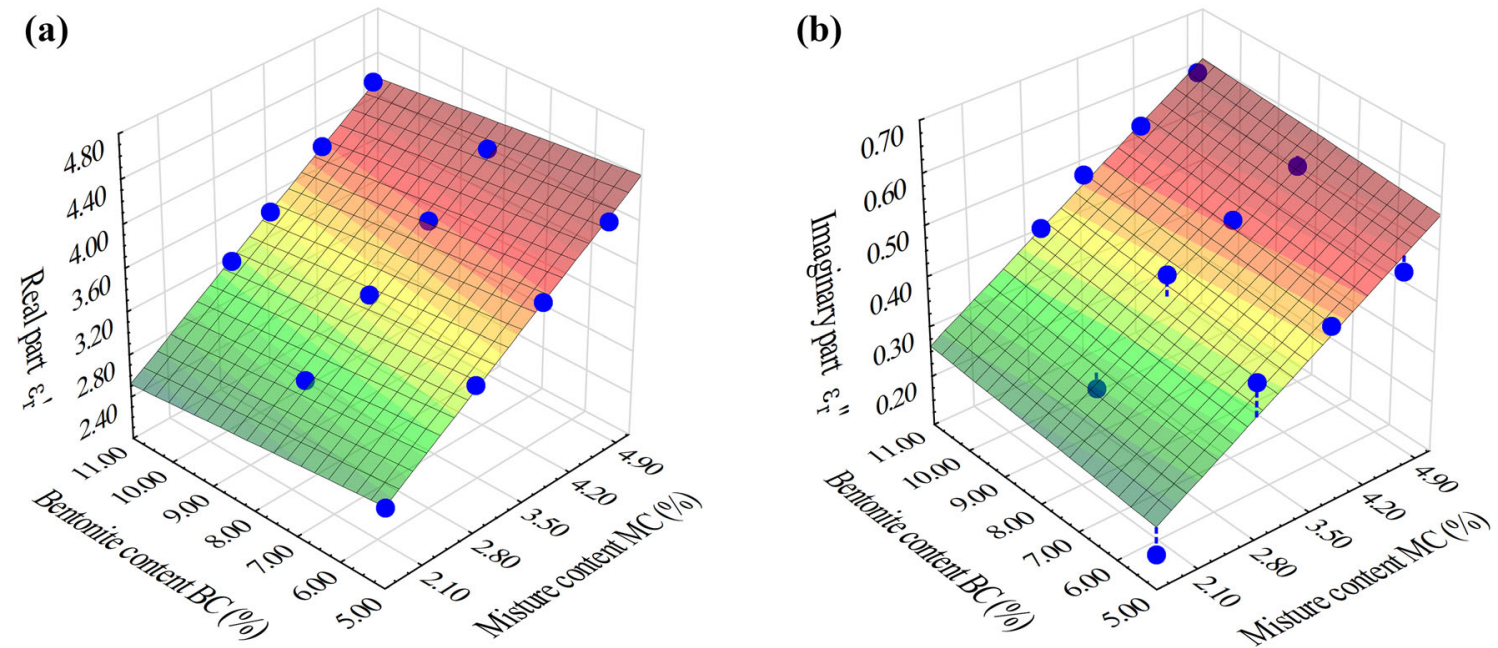

Fig. 7 The influence of moisture and bentonite content in GLB moulding sands on the $\varepsilon_{r}^{\prime}$ (a) and $\varepsilon_{r}^{\prime \prime}$ (b)

standard deviation and standard error for $\varepsilon_{r}^{\prime}$ measurements was less than, respectively, $1 \%$ and $0.5 \%$. The statistical analysis of the $\varepsilon_{r}^{\prime \prime}$ results has shown following values: standard deviation was less than $2.4 \%$ and standard error was less than $1.3 \%$. 

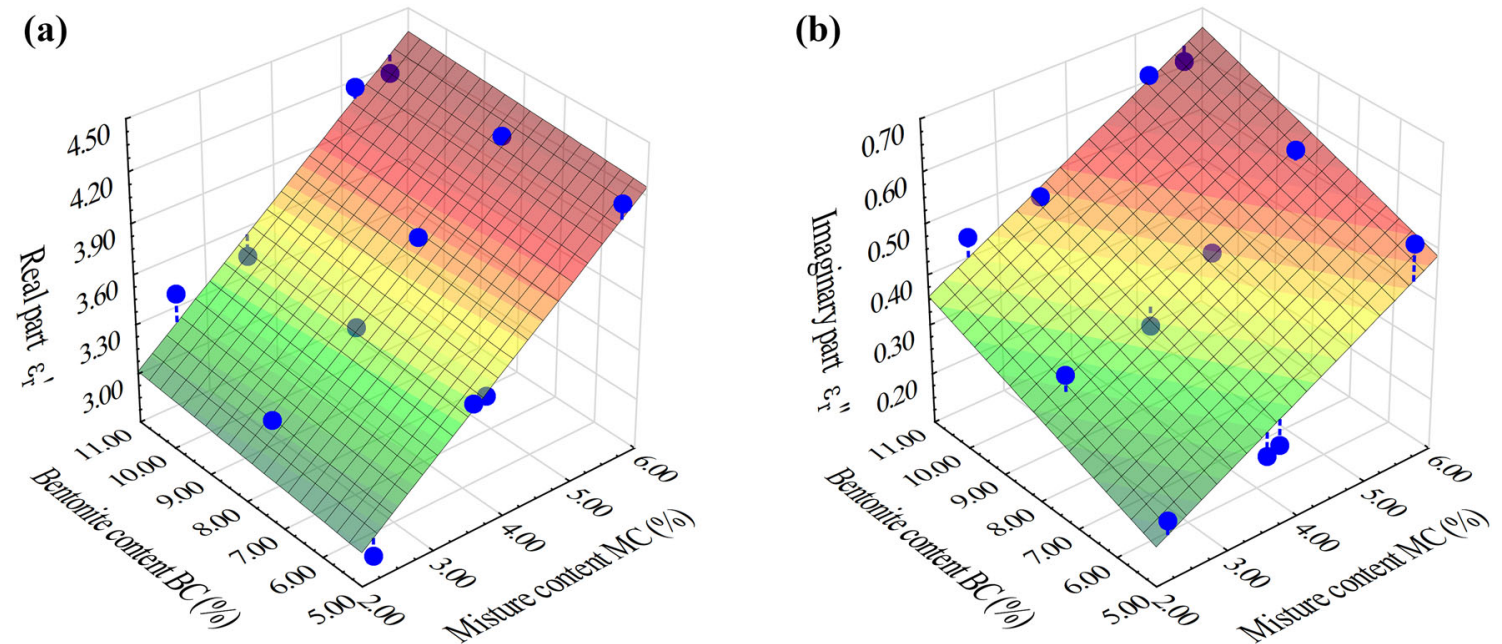

Fig. 8 The influence of moisture and bentonite content in GLC moulding sands on the $\varepsilon_{r}^{\prime}$ (a) and $\varepsilon_{r}^{\prime \prime}$ (b)

For GLB moulding sand, the highest value of $\varepsilon_{r}^{\prime}=4.16$ is determined for a moisture content of $5.03 \%$ and a bentonite content of $11 \%$. The GLB moulding sand with $1.60 \%$ moisture and $5 \%$ bentonite content has the lowest value of $\varepsilon_{r}^{\prime}=2.75$. As a result, molding sands with a higher water and bentonite content have a higher polarization ability under the influence of a $2.45 \mathrm{GHz}$ microwave field and a higher efficiency in converting microwave energy into heat. With a constant bentonite content, for example $8 \%$ for GLB moulding sand, approximately twice the water content causes 1.5 times increase in $\varepsilon_{r}^{\prime}$.

It has been confirmed that the increase in the value of real and imaginary parts of relative complex permittivity is due to both the content of the binder material and the water. The enhancement of the moulding sands permittivity by increasing the water and bentonite content can be caused by two phenomena. One of them is related to the increase of the water amount, which is a material with a relatively high dielectric permittivity $\left(\varepsilon_{r}^{\prime}=77.5, \varepsilon_{r}^{\prime \prime}=8.22\right.$, frequency $2.20 \mathrm{GHz}$, temperature $\left.25^{\circ} \mathrm{C}[41]\right)$. The second phenomenon is that there is an ion exchange and chemical reaction between bentonite and water (protonation/deprotonation of surface hydroxyls) [42].

Moulding sands (GLA, GLB and GLC) with constant bentonite content $(\mathrm{BC}=8 \%)$ and constant moisture content (MC $=3.30 \%$ ) have similar $\varepsilon_{r}^{\prime}$ values, which are 3.44, 3.41 and 3.42 respectively. A similar analysis to $\varepsilon_{r}^{\prime \prime}$ confirmed that the type of bentonite does not affect the variability of moulding sand's permittivity. As a result, one type of moulding sands (GLA) with a variable moisture content was selected for further compression strength measurements.

It has been observed that the value $\varepsilon_{r}^{\prime}$ and $\varepsilon_{r}^{\prime \prime}$ of green moulding sand of known composition increases with the increase in moisture content MC and bentonite content BC, and the nature of these relationships is illustrated by a linear function (Table 3).

These curves can be used to accurately estimate the value of based on known moisture content in the $1 \%$ to $6 \%$ o range and bentonite content in the $5 \%$ to $11 \%$ range. The large values of the $\mathrm{R}^{2}$ show that the linear regression equations obtained are very well suited to these relationships and can estimate the relative complex permittivity value of the green molding sands with a known moisture and bentonite content. As a result, quantitative and qualitative moulding sand composition will be available to meet the specific requirements of the microwave molds and cores manufacturing process [43, 44].

\subsection{Relationship Between Green Compression Strength and Relative Complex Permittivity}

Results of the measurement of the green compression strength of the moulding sand GLA, GLB and GLC with $8 \%$ bentonite, depending on real and imaginary part of the relative complex permittivity are shown graphically in Figs. 9, 10 and 11. The standard deviation and standard error for compression strength measurements was less than, respectively $5 \%$ and $4 \%$.

Analyzing the experimental results, we can conclude that the values of $\varepsilon_{r}^{\prime}$ and $\varepsilon_{r}^{\prime \prime}$ ' are inversely proportional to the compressive strength of the masses in the raw state. The nature of these relationships is described by linear functions whose detailed equations are shown in Figs. 9, 10, 11. From the presented studies (Figs. 6, 7, 8) in the study of the bentonite-water system, the significant effect of the double-valve diffusion effect was demonstrated (diffuse double layer DDL), on the introduction of pore water into the montmorillonite layers was demonstrated at high ratios solid to water (S/L) [42]. Meanwhile, studies on electrical proper- 
Table 3 Linear regression equation for the $\varepsilon_{r}^{\prime}$ and $\varepsilon_{r}^{\prime \prime}$ values of the green moulding sands

\begin{tabular}{lll}
\hline Green sand designation & Linear regression equation & Coefficient determination $\mathrm{R}^{2}$ \\
\hline $\mathrm{GLA}$ & $\varepsilon_{r}^{\prime}=2.48+0.33 \cdot \mathrm{MC}-0.02 \cdot \mathrm{BC}$ & 0.94 \\
$\mathrm{GLA}$ & $\varepsilon_{r}^{\prime \prime}=0.08+0.08 \cdot \mathrm{MC}+0.01 \cdot \mathrm{BC}$ & 0.90 \\
$\mathrm{GLB}$ & $\varepsilon_{r}^{\prime}=2.21+0.47 \cdot \mathrm{MC}-0.04 \cdot \mathrm{BC}$ & 0.99 \\
$\mathrm{GLB}$ & $\varepsilon_{r}^{\prime \prime}=0.04+0.10 \cdot \mathrm{MC}+0.01 \cdot \mathrm{BC}$ & 0.89 \\
$\mathrm{GLC}$ & $\varepsilon_{r}^{\prime}=2.14+0.34 \cdot \mathrm{MC}+0.02 \cdot \mathrm{BC}$ & 0.95 \\
$\mathrm{GLC}$ & $\varepsilon_{r}^{\prime \prime}=-0.12+0.08 \cdot \mathrm{MC}+0.03 \cdot \mathrm{BC}$ & 0.90 \\
\hline
\end{tabular}
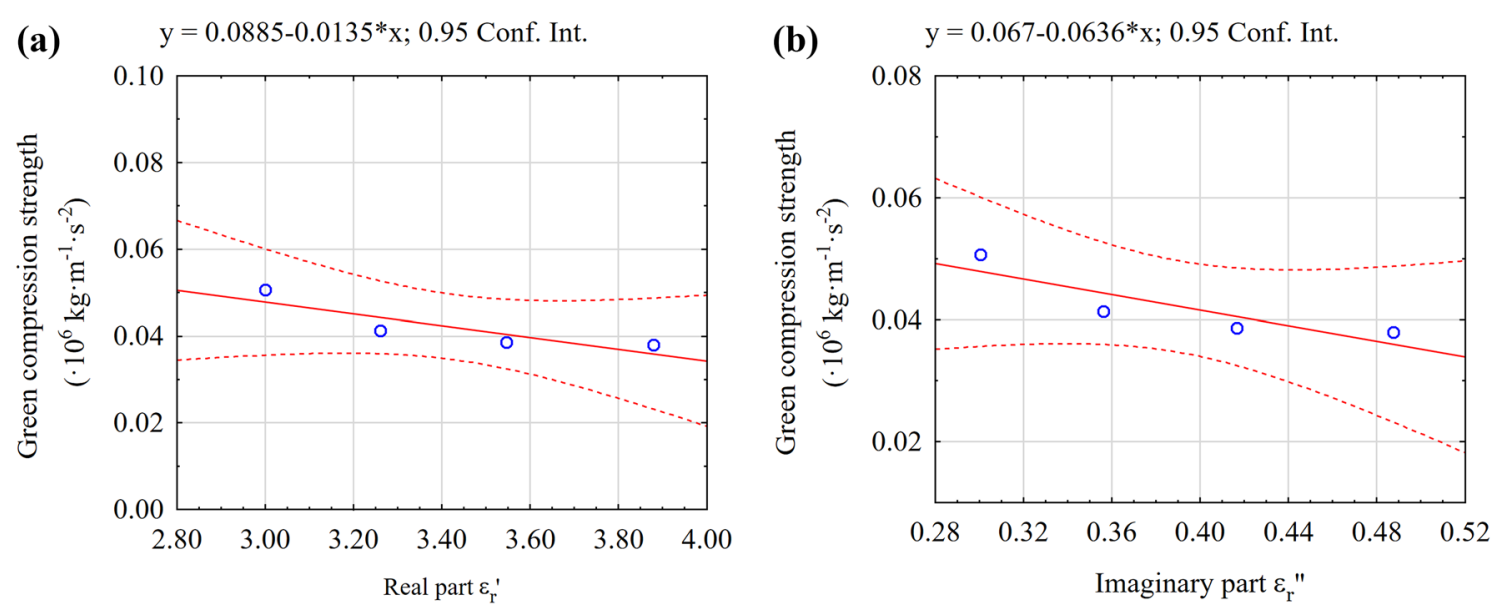

Fig. 9 The influence of $\varepsilon_{r}^{\prime}$ (a) and $\varepsilon_{r}^{\prime \prime}(\mathbf{b})$ on green compression strength of GLA moulding sand with 8\% bentonite
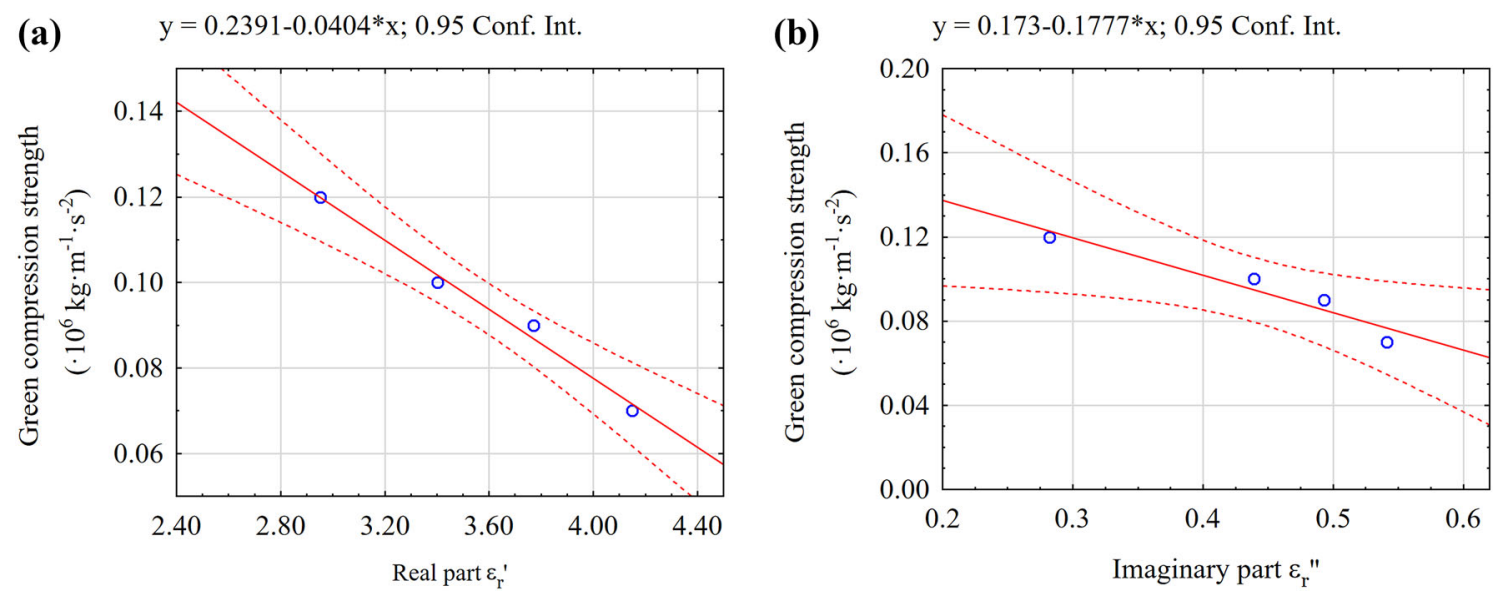

Fig. 10 The influence of $\varepsilon_{r}^{\prime}(\mathbf{a})$ and $\varepsilon_{r}^{\prime \prime}$ (b) on green compression strength of GLB moulding sand with 8\% bentonite

ties of water in clay and silty soils [7] have demonstrated that dielectric dispersion in soils, if it exists, takes place mainly in the loosely bound adsorption water layer and outer capillary water layer, both of which act as interface zones between a more tightly bound water molecular structure and a looser one.
Literature analysis and own research (Figs. 6,7,8) show that water content influences the results of dielectric permittivity. Water in green molding sands is an indispensable component, which gives strength. It can be observed that with increasing permittivity, the strength of molding sand decreases, irrespective of the type and amount of bentonite. Therefore, it can be concluded that if the composition of the 

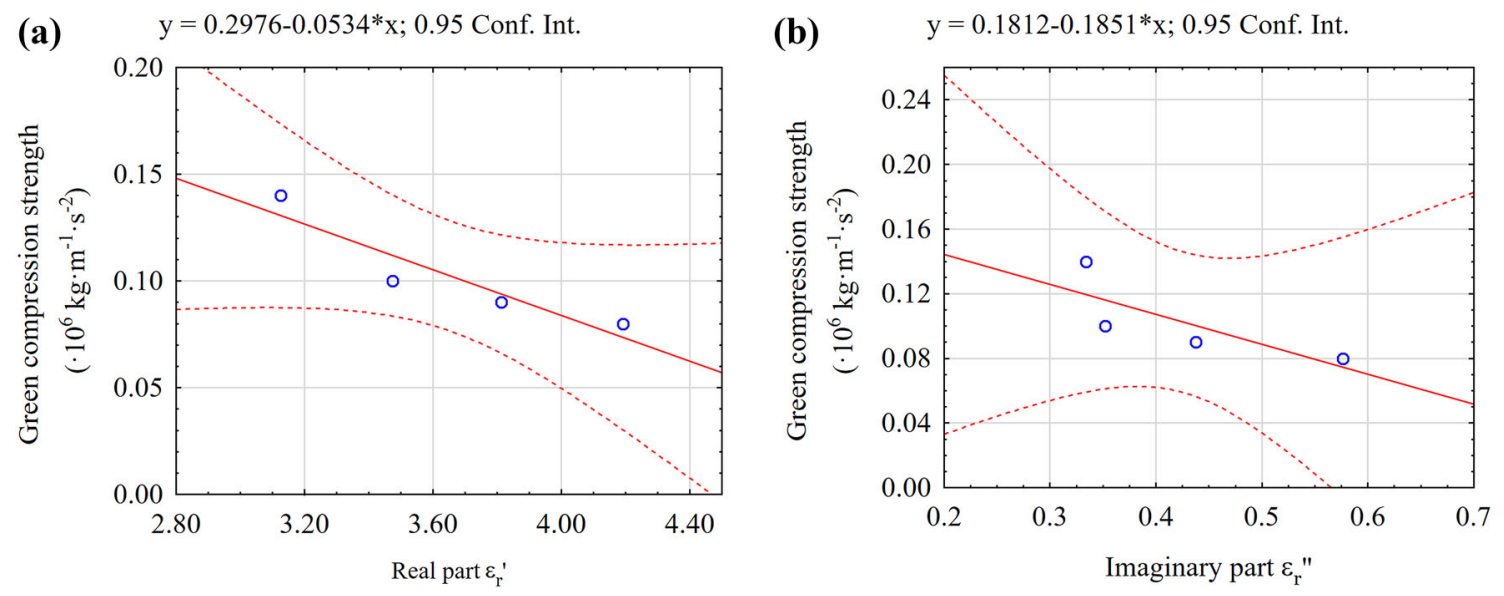

Fig. 11 The influence of $\varepsilon_{r}^{\prime}$ (a) and $\varepsilon_{r}^{\prime \prime}$ (b) on green compression strength of GLC moulding sand with 8\% bentonite

molding sand is known, at constant density, it is possible to obtain a standard curve for each type of bentonite (Figs. 6, $7,8)$. As a result, by making only one dielectric permittivity measurement, it is possible to determine the strength of a green moulding sand. Research has been conducted on quartz sand, which, due to its availability and relatively low price, is the most commonly used matrix in foundries. Therefore, to confirm the universality of strength determination based on permittivity tests, it is advisable to develop tests for other types of matrix.

\section{Conclusion}

In view of the objective of the study and on the basis of an analysis, the following conclusions were drawn from the results of the studies:

- The green compression strength and moisture content of the moulding sands can be established simultaneously by the value of real and imaginary parts of the relative complex permittivity, determined in $2.45 \mathrm{GHz}$, knowing the initial density and the bentonite content,

- Relative complex permittivity increase linearly due to an increase in the water and bentonite content. This change is due to the fact that the increase in $\varepsilon_{r}^{\prime}$ and $\varepsilon_{r}^{\prime \prime}$ is connected to the increase in water content and chemical interactions between water end bentonite,

- The compression strength of moulding sand decrease as real and imaginary part of complex relative permittivity increase,

- Microwave non-destructive testing may be used as an alternative to typical strength destructive examination,

- Using microwave testing offers many advantages, such as: reducing the amount of used moulding sands (the volume of the sample for permittivity testing is approximately
12 times smaller than the volume of the standard sample for determination of compression strength), reduction of the measurement time (the permittivity measurement takes approximately $30 \mathrm{~s}$ ), energy saving (replace two separate powered devices with one cavity resonator stand),

- Presented results can be very useful for the future design of sensor for nondestructive microwave testing of moulding sands and similar materials containing sand, water and clay.

This research did not receive any specific grant from funding agencies in the public, commercial, or not-for-profit sectors.

Open Access This article is licensed under a Creative Commons Attribution 4.0 International License, which permits use, sharing, adaptation, distribution and reproduction in any medium or format, as long as you give appropriate credit to the original author(s) and the source, provide a link to the Creative Commons licence, and indicate if changes were made. The images or other third party material in this article are included in the article's Creative Commons licence, unless indicated otherwise in a credit line to the material. If material is not included in the article's Creative Commons licence and your intended use is not permitted by statutory regulation or exceeds the permitted use, you will need to obtain permission directly from the copyright holder. To view a copy of this licence, visit http://creativecomm ons.org/licenses/by/4.0/.

\section{References}

1. Paluszkiewicz, C., Holtzer, M., Bobrowski, A.: FTIR analysis of bentonite in moulding sands. J. Mol. Struct. 880, 109-114 (2008). https://doi.org/10.1016/j.molstruc.2008.01.028

2. Schiebel, K., Jordan, G., Kaestner, A., Schillinger, B., Boehnke, S., Schmahl, W.W.: Neutron radiographic study of the effect of heat-driven water transport on the tensile strength of bentonitebonded moulding sand. Transp. Porous Media 121, 369-387 (2018). https://doi.org/10.1007/s11242-017-0968-z 
3. Whiting, L., Sadayappan, K.: Casting processes and materials. In: Sahoo, M., Sahu, S. (eds.) Casting Copper-Base Alloys, 3rd edn, pp. 23-86. American Foundry Society, Schaumburg (2015)

4. Campbell, J., Svidro, J.T., Svidro, J.: Molding and casting processes. In: ASM Handbook, vol. 1A: Cast Iron Science and Technology, pp. 189-206. ASM International, Materials Park (2017)

5. Lewandowski Lech, J.: Molding Materials. Akapit Publisher, Kraków (1997)

6. Janicki, E., Sakwa, W.: Moulding Materials Properties and Applications. WNT, Warszawa (1965)

7. Saarenketo, T.: Electrical properties of water in clay and silty soils. J. Appl. Geophys. 40, 73-88 (1998). https://doi.org/10.1016/S092 6-9851(98)00017-2

8. Sika, R., Popielarski, P.: Methodology supporting production control in a foundry applying modern DISAMATIC molding line. In: MATEC Web Conference. EDP Sciences, pp. 1-6 (2017). https:// doi.org/10.1051/matecconf/201713705007.

9. Elshennawy, A.K., Weheba, G.S.: Metal casting expendable molds. In: Materials and Manufacturing Processes, 5th edn. Society of Manufacturing Engineers (SME), Southfield, pp. 159-198 (2015)

10. Abdullah, A., Sulaiman, S., Baharudin, B.T.H.T., Ariffin, M.K.A., Vijayaram, T.R., Sayuti, M.: Testing for green compression strength and permeability properties on the tailing sand samples gathered from Ex Tin Mines in Perak State, Malaysia. Adv. Mater. Res. 445, 859-864 (2012). https://doi.org/10.4028/www.scientific. net/AMR.445.859

11. Folorunso, D., Aribo, S., Olaniran, O., Oladele, I.: Optimizing the green compression strength and permeability of green sand made from Epe silica sand. Int. J. Eng. 3, 119-126 (2009)

12. Long, W., Xia, L., Wang, X.: A rapid automatic analyzer and its methodology for effective bentonite content based on image recognition technology. China Foundry 13, 322-326 (2016). https://doi. org/10.1007/s41230-016-5119-6

13. Kaufhold, S., Dohrmann, R., Ufer, K., Meyer, F.M.: Comparison of methods for the quantification of montmorillonite in bentonites. Appl. Clay Sci. 22, 145-151 (2002). https://doi.org/10.1016/S016 9-1317(02)00131-X

14. Holtzer, M., Bobrowski, A., Grabowska, B.: Montmorillonite: a comparison of methods for its determination in foundry bentonites. Metalurgija 50, 119-122 (2011)

15. Liszka, K., Klimkiewicz, K., Malinowski, P.: polish foundry engineer with regard to changes carried by the industry 4.0. Arch. Foundry Eng. 19(1), 103-108 (2019). https://doi.org/10.24425/afe. 2019.127102

16. Ravi, B.: Metal casting 4.0: closing the loop between design and manufacturing. Trans. Indian Inst. Met. (2021). https://doi.org/10. 1007/s12666-020-02152-y

17. Ida, N.: Microwave measurements. In: Open Resonator Microwave Sensor Systems for Industrial Gauging: A Practical Design Approach, pp. 131-180. Institution of Engineering and Technology, London (2018)

18. Kharkovsky, S., Zoughi, R.: Microwave and millimeter wave nondestructive testing and evaluation-overview and recent advances. IEEE Instrum. Meas. Mag. 10, 26-38 (2007). https://doi.org/10.1 109/MIM.2007.364985

19. Li, Z., Haigh, A., Soutis, C., Gibson, A., Wang, P.: A review of microwave testing of glass fibre-reinforced polymer composites. Nondestruct. Test Eval. 34, 429-458 (2019). https://doi.org/10.10 80/10589759.2019.1605603

20. Hippel, A.R.V. (ed.): Dielectric Materials and Applications. Artech House on Demand, Boston (1995)

21. Liu, C., Zhang, L., Peng, J., Srinivasakannan, C., Liu, B., Xia, H., Zhou, J., Xu, L.: Temperature and moisture dependence of the dielectric properties of silica sand. J. Microw. Power Electromagn.
Energy 47, 199-209 (2013). https://doi.org/10.1080/08327823.20 13.11689858

22. Matzler, C.: Microwave permittivity of dry sand. IEEE Trans. Geosci. Remote Sens. 36, 317-319 (1998). https://doi.org/10.11 09/36.655342

23. Fratticcioli, E., Dionigi, M., Sorrentino, R.: A new permittivity model for the microwave moisture measurement of wet sand. In: 33rd European Microwave Conference Proceedings (IEEE Cat. No.03EX723C), pp. 539-542 (2003). https://doi.org/10.110 9/EUMC.2003.177536.

24. Robinson, D.A., Friedman, S.P.: A method for measuring the solid particle permittivity or electrical conductivity of rocks, sediments, and granular materials. J Geophys. Res Solid Earth. 108, 1-9 (2003). https://doi.org/10.1029/2001JB000691

25. Nowak, D., Gal, B., Granat, K., Jaworski, G., Więcławek, R.: Determination of moisture content in synthetic moulding sand on the grounds of relative permittivity measurement. Arch. Metall. Mater. 62, 2189-2192 (2017). https://doi.org/10.1515/amm-2017-0322

26. Piladaeng, N., Angkawisittpan, N., Homwuttiwong, S.: Determination of relationship between dielectric properties, compressive strength, and age of concrete with rice husk ash using planar coaxial probe. Meas. Sci Rev. 16, 14-20 (2016). https://doi.org/10.151 5/msr-2016-0003

27. Wang, J.R., Schmugge, T.J.: An empirical model for the complex dielectric permittivity of soils as a function of water content. IEEE Trans. Geosci. Remote Sens. 18, 288-295 (1980). https://doi.org/ 10.1109/TGRS.1980.350304

28. Nowak, D., Politechnika, W.: Prediction of Parameters of Microwave Heating of Moulding and Core Sands. Oficyna Wydawnicza Politechniki Wrocławskiej, Wrocław (2018)

29. Perzyk, M.: Application of soft modeling for detecting causes of disturbances in foundry processes, possibilities and problems, Warszawa (2006)

30. Holtzer, M., Bobrowski, A., Żymankowska-Kumon, S.: Temperature influence on structural changes of foundry bentonites. J. Mol. Struct. 1004, 102-108 (2011). https://doi.org/10.1016/j.molstruc. 2011.07.040

31. Product catalogue, Certech: (2021). https://www.certech.com.pl/ goods_category/odlewnictwo/. Accessed 19 Mar 2020

32. Sheen, J.: Measurements of microwave dielectric properties by an amended cavity perturbation technique. Measurements 42, 57-61 (2009). https://doi.org/10.1016/j.measurement.2008.03.017

33. Sheen, J.: Study of microwave dielectric properties measurements by various resonance techniques. Measurements 37, 123-130 (2005). https://doi.org/10.1016/j.measurement.2004.11.006

34. Orloff, N.D., Obrzut, J., Long, C.J., Lam, T., Kabos, P., Novotny, D.R., Booth, J.C., Liddle, J.A.: Dielectric characterization by microwave cavity perturbation corrected for nonuniform fields. IEEE Trans. Microw. Theory Tech. 62, 2149-2159 (2014). https:// doi.org/10.1109/TMTT.2014.2336775

35. Kik, A.: Complex permittivity measurement using a ridged waveguide cavity and the perturbation method. IEEE Trans. Microw. Theory Tech. 64, 3878-3886 (2016). https://doi.org/10.1109/TMTT.2 016.2614509

36. Soldatov, S., Kayser, T., Link, G., Seitz, T., Layer, S., Jelonnek, J.: Microwave cavity perturbation technique for high-temperature dielectric measurements. In: 2013 IEEE MTT-S International Microwave Symposium Digest (MTT), pp. 1-4 (2013). https://doi. org/10.1109/MWSYM.2013.6697793

37. Deshpande, M.D., Reddy, C.J., Tiemsin, P.I., Cravey, R.: A new approach to estimate complex permittivity of dielectric materials at microwave frequencies using waveguide measurements. IEEE Trans. Microw. Theory Tech. 45, 359-366 (1997). https://doi.org/ $10.1109 / 22.563334$ 
38. Skocik, P., Neumann, P.: Measurement of complex permittivity in free space. Procedia Eng. 100, 100-104 (2015). https://doi.org/10. 1016/j.proeng.2015.01.347

39. Piuzzi, E., Chicarella, S., Frezza, F., Pisa, S., Prontera, S., Timpani, F., Cannazza, G., Cataldo, A., Benedetto, E.D.: Design and characterization of a measurement system for dielectric spectroscopy investigations on granular materials in the $2.45 \mathrm{GHz}$ ISM band. In: 2015 IEEE International Instrumentation and Measurement Technology Conference (I2MTC) Proceedings, pp. 734-738 (2015). https://doi.org/10.1109/I2MTC.2015.7151359

40. Zhu, X., Guo, W., Wu, X., Wang, S.: Dielectric properties of chestnut flour relevant to drying with radio-frequency and microwave energy. J. Food Eng. 113, 143-150 (2012). https://doi.org/10.101 6/j.jfoodeng.2012.04.014

41. Kaatze, U.: Complex permittivity of water as a function of frequency and temperature. J. Chem. Eng. Data. 34, 371-374 (1989). https://doi.org/10.1021/je00058a001
42. Wersin, P., Curti, E., Appelo, C.A.J.: Modelling bentonite-water interactions at high solid/liquid ratios: swelling and diffuse double layer effects. Appl. Clay Sci. 26, 249-257 (2004). https://doi.org/ 10.1016/j.clay.2003.12.010

43. Stachowicz, M., Granat, K., Nowak, D.: Dielectric hardening method of sandmixes containing hydrated sodium silicate. Metal. Sisak Then Zagreb. 52, 169-172 (2013)

44. Mujumdar, A.S.: Microwave and dielectric drying. In: The Handbook of Industrial Drying, 4th edn. CRC Press, Boca Raton pp. 285-306 (2014)

Publisher's Note Springer Nature remains neutral with regard to jurisdictional claims in published maps and institutional affiliations. 